\title{
Problem Solving and Counter Measures for Road Accident Prone Environments
}

\author{
Geena Kuruvilla $^{1, ~ *}$, Jawahar Saud ${ }^{2}$ \\ ${ }^{1}$ Department of Civil Engineering, FISAT, Kerala Technological University, Ernakulam, India \\ ${ }^{2}$ Department of Civil Engineering, Federal Institute of Technology, KTU, Ernakulam, India
}

\section{Email address:}

geena.k0104@gmail.com (G. Kuruvilla), jawahar405@gmail.com (J. Saud)

${ }^{*}$ Corresponding author

\section{To cite this article:}

Geena Kuruvilla, Jawahar Saud. Problem Solving and Counter Measures for Road Accident Prone Environments. American Journal of Civil Engineering. Vol. 5, No. 2, 2017, pp. 69-74. doi: 10.11648/j.ajce.20170502.12

Received: January 12, 2017; Accepted: January 20, 2017; Published: February 24, 2017

\begin{abstract}
Safe roads are the foundation for the traffic safety. An accident is an unintentional injury, incidental and unplanned event that are caused by the transfer of energy between the human body and the environment. It involves a minimum of one road vehicle during which at least a minimum of one person is dislocated or killed. They impose a huge socio-economic cost in terms of untimely deaths, injuries, and loss of potential income and hence road safety has become an issue of national concern. Two main factors responsible for road accidents are heavy traffic on roads and rash driving. Reducing exposure to risk through transport and land use policies is the main factor behind the crashes. Shaping the road network for road injury prevention is one of the main step to be adopted. The main objective of this study is to describe the basic principles of road traffic injury control that differentiate the current situation of traffic accidents, and define the specific interventions that can be implemented in different settings to prevent the road traffic injuries and reduces the number of blackspots and to suggest various measures to strengthen the disaster risk governance to manage the risk of the disaster so that new efforts can be implemented to correlate the traffic accidents.
\end{abstract}

Keywords: Traffic, Accidents, Safety, Counter Measures, Black Spots

\section{Introduction}

Road accident among others occurs frequently that results in injury, death and property damage. The main risk factors for collision including vehicle design, speed of operation, road design, road environment. An accident is an unintentional injury, incidental and unplanned event that are caused by the transfer of energy between the human body and the environment. It involves a minimum of one road vehicle, occurring on a road vehicle during which at least a minimum of one person is dislocated or killed. They impose a huge socio - economic cost in terms of untimely deaths, injuries, and loss of potential income and hence road safety has become an issue of national concern. Two main factors responsible for road accidents are heavy traffic on roads and rash driving. Reducing exposure to risk through transport and land use policies is the main factor behind the crashes. Shaping the road network for road injury prevention is one of the main step to be adopted.

Climate is an important consideration for the traffic environment. For mountain roads, more attention should be paid on the impact of geological disasters induced by abnormal and severe weather.

The world's first road traffic death have occurred on 31 August 1869 and that involves a motor vehicle. There seems a tremendous increase in the death of the people after the introduction of a motor vehicle. The British road engineer $\mathrm{J}$. J. Leeming has compared the statistics of the fatality rate after the development of the vehicle and he concluded that from the period of $1863-1870$, there were 470 fatalities per million of population in different type of mode of transportation. Hence, thorough research to decrease the causes of accidents are well needed in our day to day life to save the environment. Examples of accidents occurred in 
different region is stated below.

\subsection{Road Accident Statistics in India-Delhi}

Delhi is connected by NH 1, 2, 8, 24 and has three express highways that connects it with its suburbs. One of the major accident that occurred in Delhi - Amritha Shergil Marg road on September 23 due to the improper alignment of road and heavy traffic congestions. The car crashed with another vehicle and total damages happen. Three individuals were killed and two persons were grievously injured. The highway is a $27.7 \mathrm{~km}$ three to four lanes connecting Gurgaon, Adharsh Nagar etc. There are 16.6 million registered vehicles in the city as of 30 June 2014, which is the highest in the world among all the cities most of which do not follow any pollution emission norms. Delhi lose nearly 42 crore manhours every month while commuting through public transport, due to the traffic congestion occurred. Therefore, serious efforts, including a number of transport infrastructure projects, are under way to encourage usage of public transport in the city.

\subsection{Road Accident Statistics in India- Kolkata}

Kolkata is the capital of India's West Bengal State and it records hundreds of accident day by day. Kolkata Traffic Police Authority has mentioned the measures to check the penalties, their genuineness and authenticity. Moreover, complaints can be lodged online and get redressed with optimum time. This measure not only increases convenience for the vehicle drivers as well as checks and controls corruption to a great extent. The road accident by multiple car occurred on busy office time at Rabindra Sadan -SSKM hospital crossing, Kolkata on 13 June 2006. The main reason was due to over taking and two persons were injured. It is commonly referred to as $\mathrm{NH} 6$, is a busy national highway in India that runs through Chhattisgarh, Odisha etc. The average speed of this highway is $80 \mathrm{kmph}$. The road is a part of national highway network of India, and is running over $1,949 \mathrm{~km}$ from Mumbai to Kolkata and its one of the long access controlled toll express way. Since, Kolkata suffers from traffic congestion, a network of expressways like Kona Express way, Belghoria expressway, flyovers and widening of southern stretch of Eastern Metropolitan Bypass are being created to ease up road traffic.

\subsection{Road Accident Statistics in India- Hyderabad}

The traffic on Hyderabad road has increased so much that it often becomes very difficult to cross a road. During the peak hours of the day, we find an unending stream of buses, trucks, cars, tempos, scooters motor- cycles and cycles. The drivers of the vehicles don't observe traffic rales and they try to overtake one another. The reckless drivers of buses and tracks are in the habit of drinking. Under the influence of liquor they indulge in rash driving. They drive their vehicles at top speed. They do not observe speed limits.

Ranga Reddy road connects the district headquarters which was named after the former deputy chief minister of
Andra Pradesh, K. V. Ranga Reddy. The accident occurred in Hyderabad Inamuguda Town of Ranga Reddy locale on April-1 2014. Three individuals were killed on the spot and two people were injured, when the transport and the car crashed on the edges of Hyderabad. The reason behind the crash was over speed and no road safety. The car lost control and in the wake of hitting the divider, slammed into the transport from the inverse direction. The road network consist of a two lane controlled access roads and the exit is controlled by the slip roads. The distance of the highway is $65.5 \mathrm{~km}$. A major stretch of the highway has been selected as a part of North-south corridor by the national highways development projects.

In 1966, Dr. William Haddon created the national highway traffic safety administration. He set the first federal safety standards for motor vehicles and set standards for state and local laws on drunk driving and requirements that motorcyclists wear helmets. In 1973, Haddon proposed ten strategies of countermeasures for reducing and avoiding damages based on a model of potential harmful energy transfer. The strategies focus on eliminating, controlling, modifying and mitigating energy and its effects. These ten strategies are listing below.

\subsection{Haddon's 10 Strategies for Road Traffic Injury Prevention}

To prevent the initial marshalling of the form of energy: This is usually done by discouraging the use of vehicles and designs that are particularly hazardous and by encouraging alternative travel modes.

To reduce the amount of energy marshalled: These includes the setting of speed limits on roads, making engines which are not very powerful, and installing speed limiters on existing vehicles.

To prevent the release of energy: This can be achieved by designing the vehicles and the environment such that road users do not make mistakes easily.

To modify the rate of spatial distribution of release of energy from its source: Providing pointed or sharp surfaces rounded and fatter distributes the forces over a larger area during an impact and thus reduces stresses on the body. Vehicles with appropriate crash worthiness criteria will transfer less energy to occupants.

To separate in space or time the energy being released from the susceptible structure: Separate lanes for bicycles and pedestrians reduce the probability of the riders or walkers being hit by motor vehicles. Daytime curfews for trucks in cities may reduce the amount of crashes involving pedestrians.

To divide the energy being released from the susceptible structure by interposition of a material barrier: This includes the physical road dividers on highways, and bollards and fences between pedestrians paths and roads.

To modify contact surface, subsurface, or basic structure which can be impacted: Padded interiors and absence of sharp objects prevent injury. Examples include softer car and bus fronts, breakaway poles on highways, and use of helmets 
by two- wheeled riders.

To strengthen the structure which might be damaged by the energy transfer: This includes the treatment for osteoporosis of older road users.

To move rapidly in detection and evaluation of damage and to counter its continuation and extension: Damage can be limited by efficient systems for extraction of victims from vehicles, emergency care and management of crash sites.

All those measures which fall between the emergency period following the damaging energy exchange and the final stabilization of the process. The measures include intermediate and long term repair and rehabilitation to be carried out to ensure the resiliency of the entire city.

The Hyderabad traffic department has used these strategies to reduce the act of the accidents being occurring rapidly and the strategies acts as a protecting agent to control the pattern of release of energy during accident. Their aim was to increase the resilience of the host and provide treatment and rehabilitation for the host.

\section{Problems}

Road accidents kill 382 in India every day -1682 times more than terrorism. India's daily death toll due to road accidents is more than four times the annual death toll from terrorism. Around 1,37,000 people were killed in road accidents in India alone that's quite more than the quantity of the individuals killed altogether the wars place along. Top ten cities with the highest number of crash deaths includes Delhi, Chennai, Mumbai, Kanpur, Lucknow, Agra, Hyderabad, Pune, Jaipur, Bengaluru. Speeding is the basic causes of road accidents.

The variability of speed and the risk of pedestrians due to speeding is very high. If the speed limit is below 50, twentyfive per cent risk of death to pedestrians. If the speed limit is ninety per cent the risk of death to pedestrians seems to be at ninety per cent. Speeding is typically the easiest factor to control, and a small reduction in vehicle speed yields disproportionate results in terms of safety.

A pedestrian struck by a car driving at $38 \mathrm{~km} / \mathrm{hr}$ has an average risk of death of $10 \%$, according to a study of safety managers. The two wheelers are the main cause of accidents of about 31.5 percent. Next priority is given to car, taxis of about seventeen percent. And then trucks of about 11.4 percent. Pedestrians to about ten, auto rickshaws for about five percent. It is recommended to have an efficient support system and training for the people manning the ambulance. Also, awareness should be created among public. Hence, unorganized traffic can be more efficient in scenarios where vehicles vary largely in their speed capabilities and size. Indian traffic is a clear example where vehicle sizes vary from two wheeled motor bikes and three wheeled auto rickshaws, to buses and trucks. For e.g., use child safety car seats, bicycle helmets, smoke alarms etc. The following are the steps to be adopted to solve the problem stated above.

\subsection{Classifying Roads and Setting Speed Limits by Their Function}

Many rad have a wide range of functions and are used by different types of vehicles and by pedestrians with large differences in speed, mass of vehicle and degree of protection. In residential areas and on urban roads it leads to conflicts between the mobility of motor vehicle users on one hand and safety of pedestrians and cyclists on the other. Classifying roads functionally in the form of a road hierarchy as it known in highway engineering is important for providing safer routes and safer designs. Such a classification takes account of land use, location of crash sites, vehicle and pedestrian flows and objectives such as speed control.

\subsection{Improving Visibility of Road Users}

Seeing and been seen are fundamental factors for the safety for all road users. The various ways to improve the visibility are the use of day time running lights on the front of the motorized vehicles, which improves the visibility while travelling during daylight hours. Also the use of reflective and protective clothing which increases the visibility of riders during the night and thus reduces the probability of crash.

\subsection{Promoting Crash-Protective Vehicle Design}

Crash protection features provide greater levels of injury protection to the drivers and passengers in the vehicle. It includes the padded instrument panels, laminated windscreens fastened to the car to prevent ejection, door locks that prevent doors from opening during a crash. The car absorbs the impact of the crash, not the driver or passengers. Head rests are important safety measures and should be fitted to all seats front and back. If certain improvement in roadway and automobile designs is done, then injury and deaths can be steadily reduced. Coalition to promote road and automobile safety, such as together for safer roads brings together global private sector to collaborate on improving the road safety.

\section{Precaution Measures}

Road safety initiatives have developed a national safety policy that was approved by the government of India. The ministry has requested all states for setting up of state road safety council and district road safety committees, and to hold their meeting together. The meeting should be carried out in such a way one among the top head, intermediate manager, and local leader should attend and pass fundamental information to the society. Tightening of safety standards for vehicles like Seat Belts, Power-steering, antilock braking system etc. should be strictly used. Providing cranes and ambulances to various State Governments under the National Highway accident relief service scheme for development on National Highways.

\subsection{Bypasses and Ring Roads}

All cities should relate to efficient ring road system as well 
as bye pass system. Ring roads which helps to avoid the by passable traffic that makes the city violate. Likewise, all major junctions catering heavy traffic should have fly overs or underpasses for providing unhindered movement of traffic.

\subsection{New Road Construction and Road Construction Quality}

Advance action is required to finalize the alignment of the new road development and ensure the Right of Way freed from encroachments in advance. Modernization in design as well as construction procedures is required to attain an ecofriendly and fast construction of the Road project. The use of modern imported machineries for construction of the pavement increases the life span as well as quality of the construction. Policies are to be adopted in such a way to provide strict quality control on each construction as per the design norms and technical specifications and the contracting agency is fully responsible for the construction quality over the service period.

\subsection{Road Maintenance and Pedestrian Safety}

Maintenance should be carried out frequently to save vehicle operating cost besides providing a very cost effective option to improving traffic flow and safety. If timely maintenance is not carried out, the asset will deteriorate over the period and render service less. The Government must give top priority to maintain the precious road assets.

Pedestrians are vulnerable road users and therefore they must be regarded as a traffic unit in planning and designing the traffic facilities. The development plan should be prepared on a human scale and must accord adequate priority to the safety of pedestrians, while formulating the scheme. It is required to provide of adequate sidewalks and maintain them in proper usable condition to promote better usage and safety of pedestrians. Zebra crossing and guard railing should be introduced wherever required.

\subsection{Parking and Drainage}

Due to the absence of parking lots and road side parking facilities, people used to park vehicles on carriageways and even foot paths. These causes traffic congestion and accidents. Policies are to be formulated to analyse the traffic demand and provide enough parking facilities on all roads considering the future traffic demand also. Lack of adequate drainage facility has been one of the major reasons for pavement failure and this causes frequent road accidents. To solve this problem built-up drain should be provided at least in urban areas.

\subsection{Street Lighting and Road Signage}

Most of the roads are not having proper street lights and this makes driving cumbersome during night time. The black topped surfaced pavements are very poor in visibility and the absence of lighting adds up difficulty. Mandatory check-ups are to be formulated to maintain proper lighting on all road corridors in the state.
Unscientific implementation of traffic control devices and installation of sign boards by various agencies in different ways, should be controlled in confirmation with standards. Too much sign boards of different kind and different types at close intervals do not serve any purpose rather than confusion and accident proneness. Application of cones, barriers etc. on carriageways results in heavy breaking or sudden drifting of vehicles and increases accident proneness.

\subsection{Rigid Pavement for Flood Prone Areas}

Government will have to take initiatives to encourage construction of rigid pavement on areas prone to flood and high traffic intensity so as to minimize recurring maintenance cost and obstruction to traffic movement while repairs. The rigid pavement, consist of a series of layers with the highest quality at or near the surface of pavements. Pavement grants friction for the heavy vehicles thus providing comfort to the driver and transfers the traffic weight from the upper surface to the natural soil. It is used by vehicles and pedestrians.

\subsection{Road Furniture}

Standardized Traffic signaling and proper road markings and signs should be made mandatory on all roads and junctions. The advancements in traffic signal systems on leading countries should be utilized for creating highly efficient and capable vehicle actuated type signal systems.

\section{Implementation of Road Safety Action Plan}

Road safety should be valuated preferably to reduce the traffic incidents occurring in day to day environments. The following steps to be implemented to maintain the road safety of the entire environment.

\subsection{Licensing System}

Licensing system should be amended to international standards. Each learner should have to be tested for their knowledge related to basic vehicular design, traffic rules and regulations, road markings, traffic signalling and the mandatory rules, safety culture to follow on roads during day as well as night driving and various types of parking.

\subsection{Parking and Drainage}

At present, more than 80 percent of transport is handled by personal modes such as cars and two wheelers. Two wheelers are involved in 40 percent of accidents and they are the victims in 25 to 30 percent fatal accidents. It is necessary to increase the share of public transport by enhancing their safety aspects and easy availability at economical cost.

\subsection{ITS Application}

The government will have to take steps to encourage harnessing latest IT and GIS based technology in traffic management, fleet management, trip scheduling, traffic 
enforcement and road safety.

\subsection{BRTS, Mono, Metro and Suburban Rail}

Modern means of public road transport system such as Bus Rapid Transit system (BRTS), bus priority schemes, mono rail, metro rail etc. should get due consideration in higher level cities. The state government is thinking alternative options for reducing traffic congestion on the existing roads. One of the options under consideration is development of Suburban rail corridor by utilising the existing rail tracks in the state. Introduction of Suburban rail between the Central Business District and its suburbs, or other locations will attract large number of commuters to railway and release congestion and accidents threats on roads.

\section{Countermeasures of Road Safety in Disaster-Prone Environment as a Civil Engineer}

Safety is to prevent road users from being killed or seriously injured. Road safety is to prevent road users from being killed or seriously injured. Road safety should be managed by each consumer in our country. Safe road design implements the reduction of black spots. Blackspots are the critical areas which seriously cause accidents. The fundamental strategy of a secure system approach is to make sure that within the event of a crash, the impact energies stay below the brink probably to provide either death or serious injury. Civil engineers play an initiative role in maintaining the road safety. Certain systematic recommendations on road disaster prevention are proposed as follows:

\subsection{Recognizing the Road Environment as an Interactive Organic System}

The roadside environment is affected by the weather conditions, the road alignment, the pavement material, the traffic flow, the protective equipment, the geological and hydrological conditions and the social economic and human environment. where the weather conditions include rain, fog, snow, wind, lightning, dust and high temperature; the road alignment factors always include the standards and the combinations of vertical and horizontal curves; the road conditions considered are slip resistance, flat, pits, wet, snow and ice, hydrops, roadblocks, etc.

\subsection{Emphasizing Highway Planning and Field Investigation}

Because of the characteristic of linear zonal distribution, sometimes the roads in mountain areas are difficult to avoid passing through some bad geological areas, where the environmental geological disasters often took place in forms of sudden, relevant and mass outbreak, giving rise to other types of secondary disasters.

Therefore, we should strengthen the pre-planning field survey and investigation, analyse the regional tectonic environment and the hydrogeological environment, establish the environmental engineering geological assessment model, demonstrate the regional stability and provide reasonable recommendations for road construction.

\subsection{Strengthening the Monitoring of Severe Weather and Risk Assessment}

Weather forecasting and risk assessment should be strengthened for heavy rain, fog, snow, strong wind, lightning, heat, cold and so on. Meanwhile, the information should also be timely released to the public by radio, television and other media, which can improve.

\subsection{From the Literatures Reviewed Following Can Be the Measure Which Helps to Prevent Traffic Accidents}

Slow down the vehicle is an important criterion for preventing traffic accidents. Speed limit is fixed for each type of roads. The speed limit should be followed regularly even if we found every other car is surpassing it. Police should be alert in looking for speeders and corrective punishment should be given genuinely. Usually people have a mentality to overtake each other. Avoid the urge to move fastly due to vigilante. Weather conditions are one of the important phenomenon that should be considered while travelling. Always we should keep windshield wipers going in the rain or snow. Headlights should be used and maintained to see ourselves as well as for the comfort of others. There is a tendency for the people to think no one is there so to break out the red signals. Always use the signals, even if no one is there. We should signal at least a couple of seconds in advance so others know what you are going to do before you do it. We should have the habit of staring at the back of the car ahead of you. Doing this, we can spot out potentially dangerous situation before it happens and can avoid a hazard that results in vulnerable situations.

\section{Conclusion}

Due to the harsh natural geographic and environmental conditions, road disasters are difficult to avoid, and often cause a devastating impact on traffic safety. It can be seen that the factors affecting road safety are complex, and include not only an accident chain composed of road geometry factors, traffic conditions and human factor and vehicles, but also the disaster-prone environment with varied geological structures, topography, climate and hydrological conditions. Implementing the data base management support chains will be effective in India. Existing studies on road safety in the disastrous weather and disaster-prone environment are very poor, and have mainly concentrated on urban roads in the relatively economically developed eastern plain area. Generally, the loss caused by the geological disasters and disastrous weather will be devastating. Therefore, importance should be attached to the disaster-prone mountain areas where the constructing and operating conditions are relatively poor, and economically underdeveloped. Road 
Safety aspects for all modes of transport need to be given due priority.

The aspects of road safety should get governmental attention such as Creation of accurate Accident Data Base along with site inspection report by independent and competent authority and accident. Investigation, analysis and corrective measures if any to the geometry, pavement surface or proper road safety training. In actual operation, future efforts should not skim the surface by designing redundant greening and landscapes in developed areas, but also increase the investment on road safety research in disaster-prone environment. Some comprehensive countermeasures are proposed to ensure the safety of the road structure, vehicles and the roadside environment so that we can save each life. No cause, no worries, no harm, to existing environment.

\section{References}

[1] Roberts. I, Education on Traffic Calming, Journal of Traffic management, Australia, June 2012, PP. 1-7.

[2] Li Kungag; Critical Issue for Road Accidents in Developed Countries, Journal of Road Safety Engineering, July 2008, PP. 23.

[3] St. Louis, Missouri, Improving Road Safety Risk Management, Journal of Traffic management, Iran, January 2012, PP. 101-111.

[4] Abdelaty, Accident Analysis and Prevention, Journal of
Traffic and Transportation Engineering, January 2015, PP. 2128.

[5] Tiwari G, Mohan D and Robertson L. S, Implementing Specific Interventions to Prevent Road Traffic Injuries, Journal of Transportation engineering, Singapore, April 2011, PP. 63-73.

[6] Disaster Management Act 2005, by Ministry of Law and Justice, New Delhi, December 2005, PP. 1-28.

[7] Fenoosky, Pena- Mora, Mani Golparvar-Fard and Zeeshan Aziz, Supporting Civil Engineers during Disaster Response and Recovery of Disaster Management, Journal of Construction Management, UK, May 2012, PP. 448-454.

[8] Guohe Guo, Zunlan Cheng, Guoxiong, Problems and Counter measures of Road safety in Disaster- Prone Environment, Journal of Transportation engineering, Tibet, June 2012, PP. 2443-2451.

[9] Guo, Fang, Road safety management, Journal of Traffic and Transportation Engineering, May 2013, PP. 22-31.

[10] Zhang, Yue. P, Evaluation on Road Side Environmental Safety and Disaster Prevention and Countermeasures for Roads (Highways), Journal of Road Safety Engineering, June 2009, PP. 120-145.

[11] Jiang, Luo, Disaster law and Prevention Principle for China Mountain Road, Journal of Traffic and Transportation Engineering, China, Feb 2012, PP. 11-16.

[12] Angela H, David Crandall, Reforming Freight Transportation System Using System Thinking, Journal of Traffic and Transportation Engineering, Australia, April 2013, PP. 28-36. 